\title{
The Effect of Structural Skeleton on the Internal Architecture Space
}

\author{
Adil A. M. Elhassan ${ }^{1}$ and Rawan Mohamed Abdalla Awad alla ${ }^{2}$ \\ ${ }^{1.1}$ Department of civil Engineering, College of Engineering, Taif University, Kingdom of Saudi Arabia\& \\ College of Engineering, \\ ${ }^{1,2}$ Sudan University of Science and Technology, Khartoum, Sudan, \\ ${ }^{2}$ Formerly graduate student, College of Architecture and Planning, Sudan University of Science and
} Technology, Khartoum, Sudan

\begin{abstract}
:
The study investigates the architectural space and its definition and the stages of development of the architectural space according to the previous civilizations up to our current era and then defining the internal space and its determinants. A historical study of the space and its value as well as the elements of the internal architecture all, were discussed in this study. The construction, the constructional structure its characteristics were defined and the constituents of the building as well. In addition, identifying the types of buildings in terms of from their functional and constructional aspects, and then identifying the constructional materials used in the constructional skeleton and their impact on the constructional skeleton in the design from several aspects until reaching the internal space and the factors affecting it. The research problem and the research objectives were defined, which is coming to design solutions and interrelated constructions as well as designing the buildings in a manner that respects the environment, taking into consideration the financial cost of the building, while minimizing the effects of construction, all of which on the internal space. The most important findings of the study are that the elements of the interior space are all interconnected and cannot be separated from each other; this is in order to reach the appropriate visual formation of the space. The elements of the internal space of the building should be evaluated by specialists in this field, is a first step before studying the selection of the most appropriate constructional skeletons of the building, before preparing the new engineering drawings, and choosing the most proper ways to protect the constructional elements during the processing of internal space processing to ensure that the cost will not increase.
\end{abstract}

Keywords: Structural; Skeleton; constructional; elements; Space.

\section{Introduction}

The construction consists of constructional elements (pillars, tiles and walls) by which the designer reinforces his idea and perceives it [1]. These elements have something that distinguishes them from other similar in other buildings; this distinction is due to the value expressed by these buildings, whether materialistic or spiritual. The construction is linked to the concepts of repetition, model, simplicity, as well as the standard, random and complex concepts. Here the ingenuity of the designer in dealing with the original elements and the selection a constructional skeleton that suits the function of the building and its internal space will be demonstrated. The construction is not separate from the architectural design process. The adopted constructional system with its elements has an essential role in terms of shape and function. It also plays an enormous role in determining the aesthetic standards of the building [2].

The process of planning and designing man-made spaces is part of the operation of the environment design that human beings occupy. Thus, internal architecture, as stated in the British Britannica (Encyclopedia) 2007, is part of the concept of architecture in general. Although man's beautiful tendency towards the environment is as old as the civilizations however, but the fields of internal architecture are relatively modern [3]-[4].

Earlier, internal architecture is often seen as a process of decorating the interior space, away from the process of space shape design, which has often been left to the architect [5]-[6]. The decorative concept has long been prevalent throughout the early 20th century. The internal designer was concerned 
with internal decorations, such as walls, floors, ceilings, and roofs, furniture, etc., in a way that formed a brilliant example. In the 20th century, internal architecture became a technical specialty based on a set of rules, systems and sciences. It is concerned with the process of creating the internal space by studying the functions of this space and its association with other interior spaces. Create an inner void by examining the purposes of this vacuum, and its relation to other domestic spaces, and then considering the aesthetic foundations and concepts that will be expressed by the designer in his or her formulation of the contents of this space, in a way that coordinates with a particular model or specific artistic vision of design [7].

Construction is defined as the system the building takes, and the balance is achieved by a particular image. The construction can also be described as the arrangement and system in which the constituent parts of the building are assembled for the purpose of maintaining the shape balanced, and its primary goal is to resist any loads that the building may experience and then move them to the ground, that is, the construction is a system to withstand loads and ensure that the building is a balanced status [8] $-[9]$.

\section{Objectives of the study}

The main objectives of this research are summarized as follows:

- Shed light on the internal architectural space and its relationship with the constructional skeleton and then analyzing the relationship between them.

- Draw up guidelines that help the architect to prepare well and planning with familiarity with all elements of the internal spaces.

- Submit proposals to regulate the relationship between the constructional designer and the architectural designer to work within one team when designing the facilities.

- Know all factors influencing the selection of the appropriate constructional skeleton of the building.

- Find integrated, architectural, constructional, and design solutions for the building.

\section{Research Methodology}

The methodology of the research is limited to the theoretical aspect, where information was collected from references and sources relevant to the subject under investigation.
A questionnaire was designed and randomly distributed to a sample of professionally experienced engineers in architectural and constructional design and supervision of constructing the facilities in order to obtain different opinions. The parts of the questionnaire are:

- Section one contains the concept of the relationship between engineers and their understanding of the role of each engineer individually.

- Section two includes the relationship between constructional design, internal architectural design, internal repairs of the building and the financial cost.

- Section three contains the constructional solutions and the factors influencing them and then analyzing these results and discussing them to find the best solutions.

\section{Discussion of the Results:}

\section{Section I: General results of the study:}

The objective of the study is to identify the elements of the internal space that affect the selection of the appropriate constructional skeleton. Several points have been reached:

1. Identify the most critical aspects of the internal space, which are: (scale, colors, lighting, texture, materials and finishing objects, furniture and accessories).

2. Elements of the internal space are a system that all interconnected and cannot be separated from one another, in order to reach the visual formation suitable for space.

3. The evaluation is comprehensive of all elements of the internal space of the building done by specialists in this field, and is considered a first step before studying the selection of the most appropriate constitutional skeleton of the building and before the preparation of the new engineering drawings.

4. The most proper methods should be chosen for the protection of inherent elements while carrying out internal space processing

5. Linking the design aspect with the constitutional reduces cost and provides aesthetics.

\section{Section II: Results of the questionnaire and the study of the current situation:}

The survey was distributed among engineers and designers in all fields of engineering with various degrees to find out about the different views on the impact of a constitutional skeleton on the internal architectural space and the challenges and obstacles they face to handle the internal space. 
By studying the results of the questionnaire analysis, it was noted that:

1. There is no sufficient scientific research that dealt with the subject of internal space and its obstacles. It either focuses on the constitutional aspect only or focuses on the architectural design, so there is a need for scientific research that deals with all issues of the internal space and everything that affects it.

2. Engineers also have a desire to use the best solutions in their designs if they have the suitable opportunity.

3. Prior to execution, it is necessary to know all the constitutional solutions that help to ensure the continuity of the building and not being exposed to dangers.

4. Focus on everything that affects the constitutional skeleton and the internal architectural space together without considering that each of them is a stand-alone design.

5. The cost has a great role in choosing the constitutional skeleton and internal design.

6. There are some buildings designed for a particular function and when the function of the building changed later, it leads to the modification of the internal space to suit the function of the new building, the thing which many real estate owners are unaware of.

The first section of the questionnaire showed the following results (Figures 1, 2, 3 and 4).

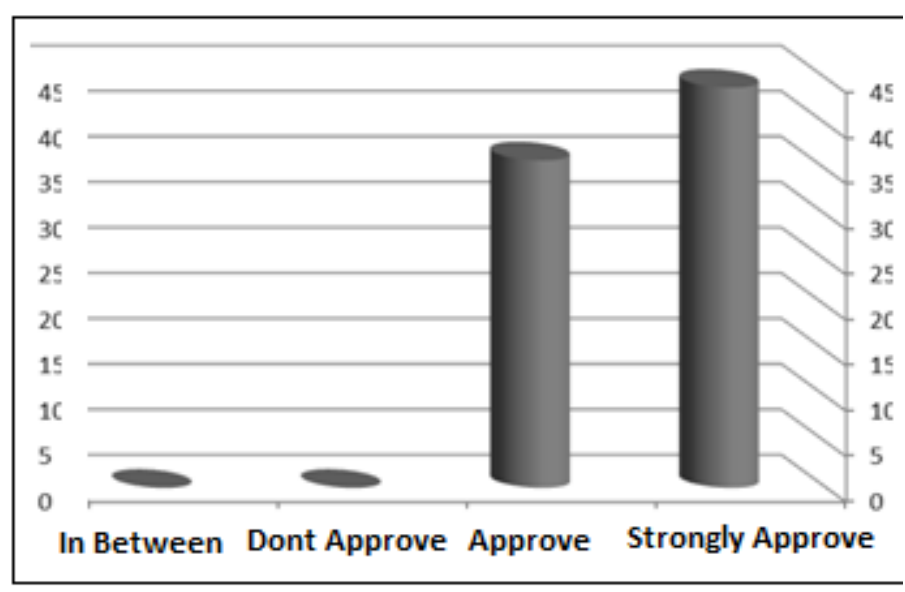

Figure 1: The relation among the civil- architectural engineers and the internal designer

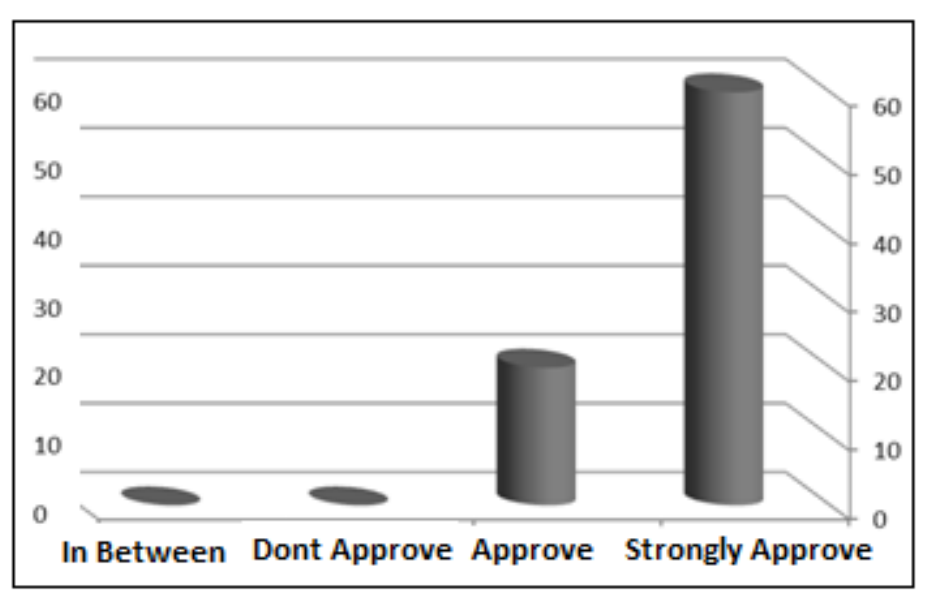

Figure 2: The consideration of environmental requirements should be taken in the design

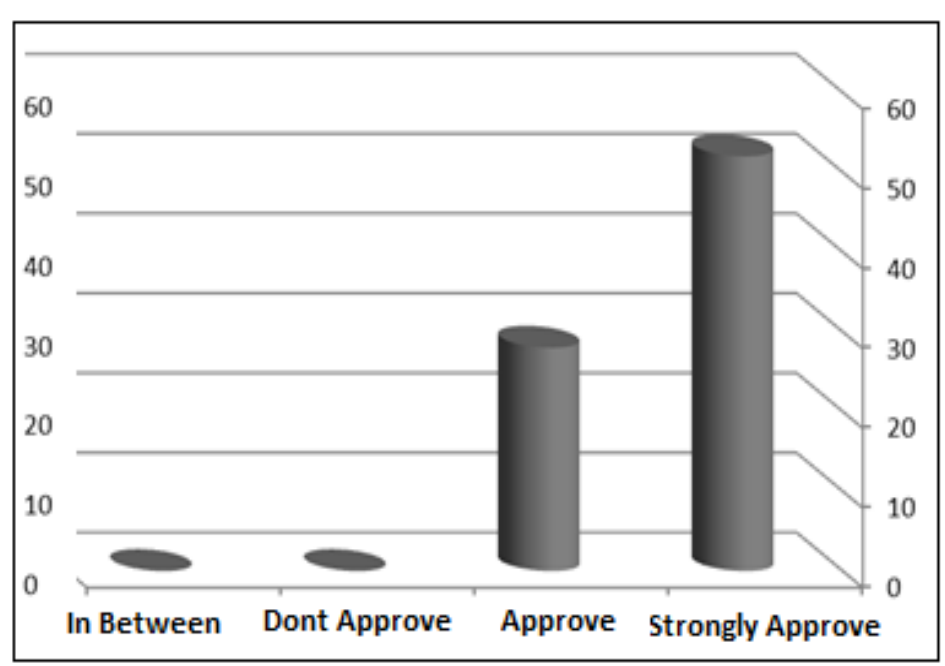

Figure 3: The consideration of cost should be taken in the design

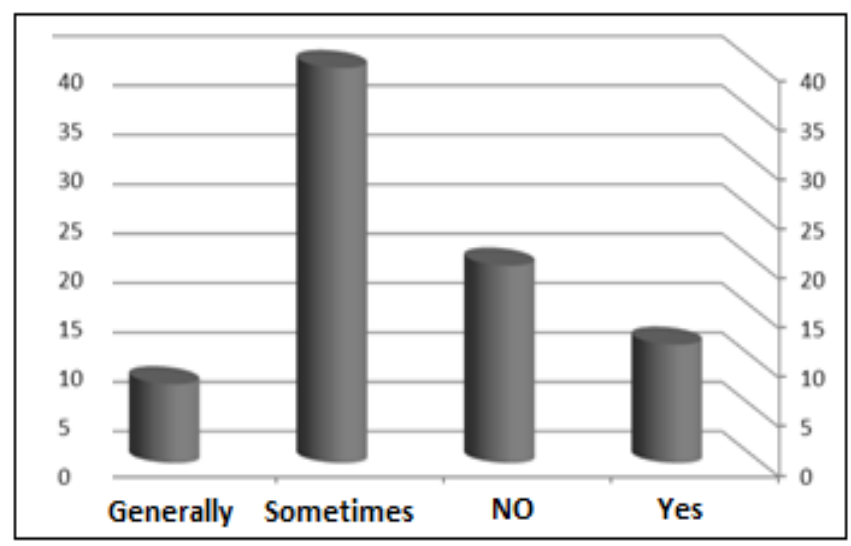

Figure 4: Use of low-cost materials

- Most people strongly agree that the relationship between engineers must be synchronized until the end of the project to avoid any obstacles that appear during the execution of the design.

- Some engineers believe that the architectural designer can replace the internal designer because most consider that the internal designer is regarded as a gustative rather than relative away from any challenges. 
- When designing, the environment surrounding the design or the building must be deemed to be compatible with all areas surrounding it.

- Most of them firmly believe that the cost of the building should be taken into consideration when designing the building in terms of the constructional skeleton and when designing the internal space design.

- Although some people agreed that the cost should be taken into account when choosing the design but a significant proportion of engineers also does not encourage the use of low-cost construction materials because it reduces the quality of internal design.

- The questionnaire showed that cooperation between engineers leads to solutions with lower cost and better quality, resulting in a model that is almost perfect.

By analyzing the results of the second section (the relationship between constructional design, internal design and internal modification of the building spaces), the following was reached (Figures 5, 6, 7, 8, 9 and 10).

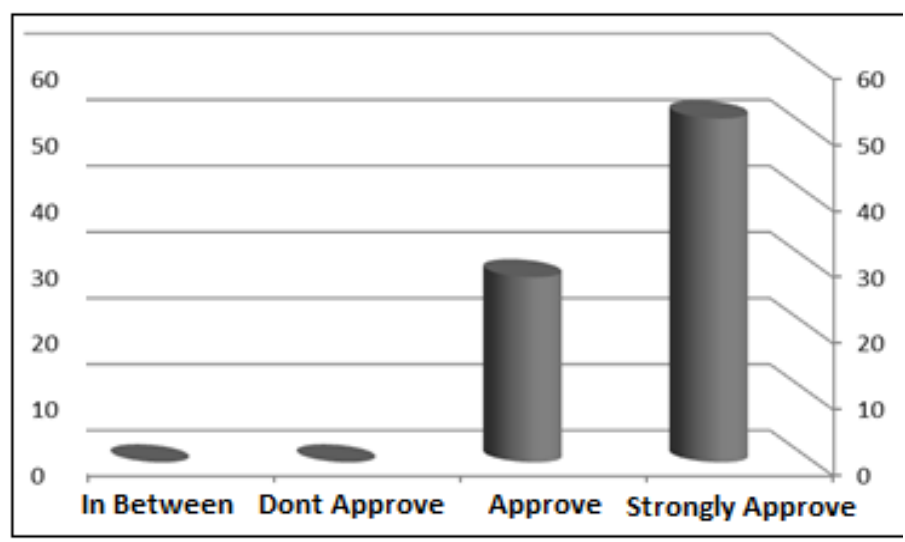

Figure 5: Should the structural design be selected according to the type and function of the building?

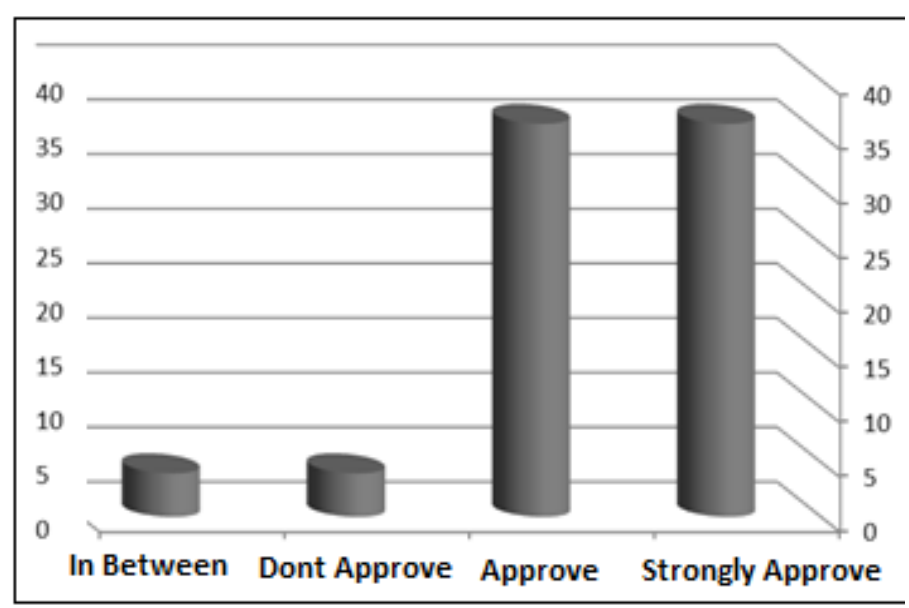

Figure 6: The consistency of construction and design - architectural design first then the structural design should be made?

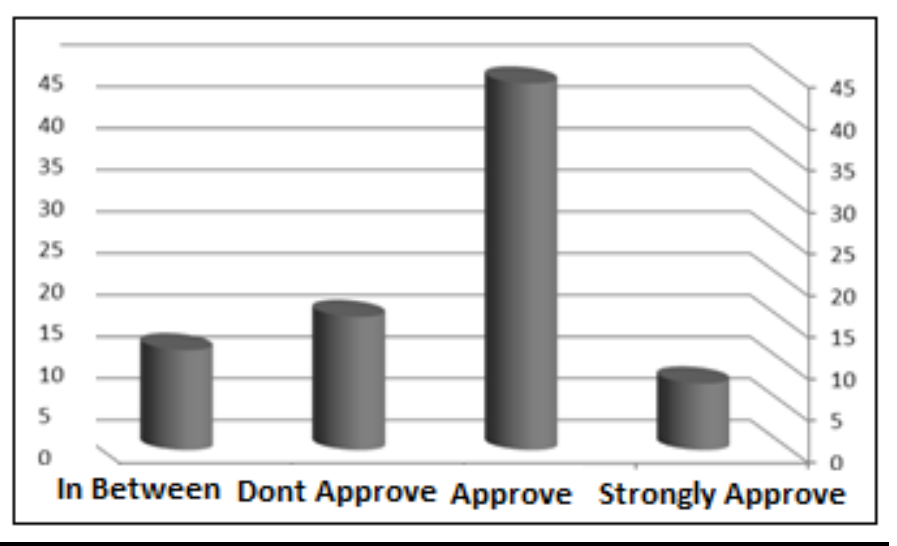

Figure 7: Constraints in the structural design - You face many obstacles in your design because of the structural design?

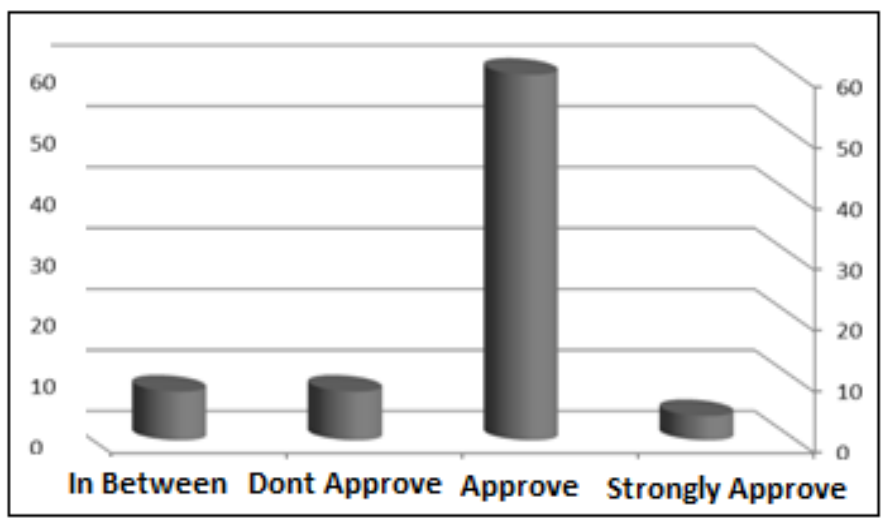

Figure 8: Determination of construction method to design the space - the structural design imposes a specific design of the inner space?

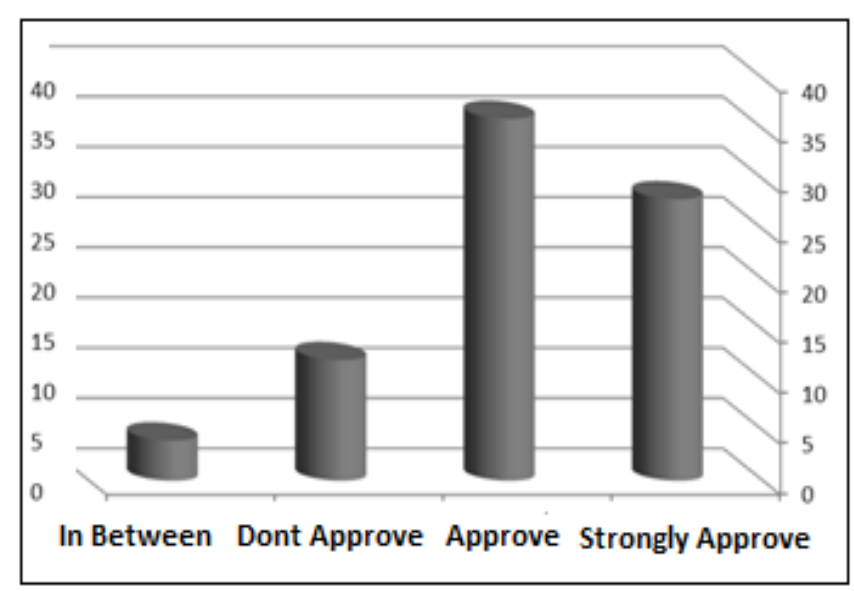

Figure 9: The suitability of construction to the function of space - Using of unsuitable structural design for the function of the building leads to many losses to address the internal space of the building 


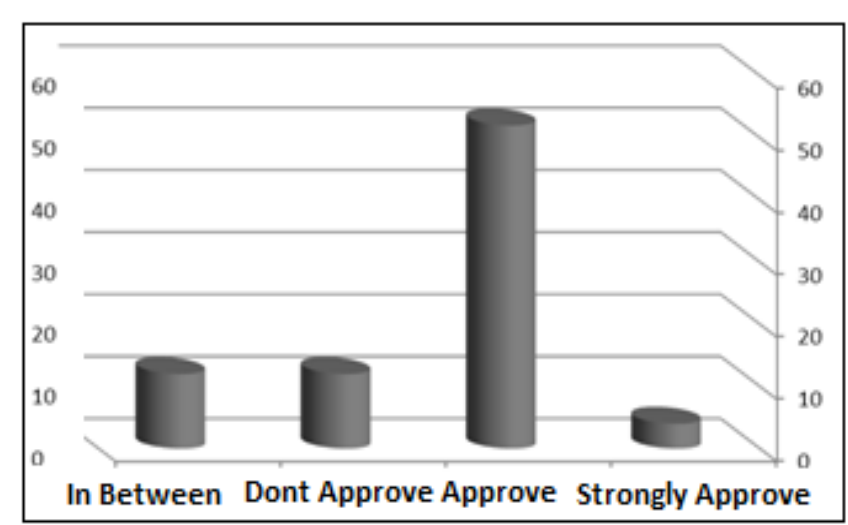

Figure 10: Effect of construction on the cost of finishing - Structural design affects the physical cost of finishing of the internal space?

- The most significant percentage of the sample proved that the function of the building has a great effect on the selection of constructional skeleton because it affects the function of the space internally.

- The percentage of people in agreeing on the design of the building first and then choosing a suitable constructional skeleton for the design because the choice of skeleton dramatically hinders creativity in the design.

- A large proportion supports the idea that the designing constructional skeleton first imposes a specific internal space that forces the designer to handle it according to the need of the building.

- People also support that the idea the unsuitable design of the constructional skeleton of the function of the structure leads to a substantial loss of internal space handling and increases financial cost of the finishing works.

- Many agreed that sometimes the higher the distance between the physical path and the natural path the more the constructional problem is

By analyzing the results of the third section (constructional solutions), the following results were reached (Figures 11, 12, 13, 14, 15, 16, 17 and 18).

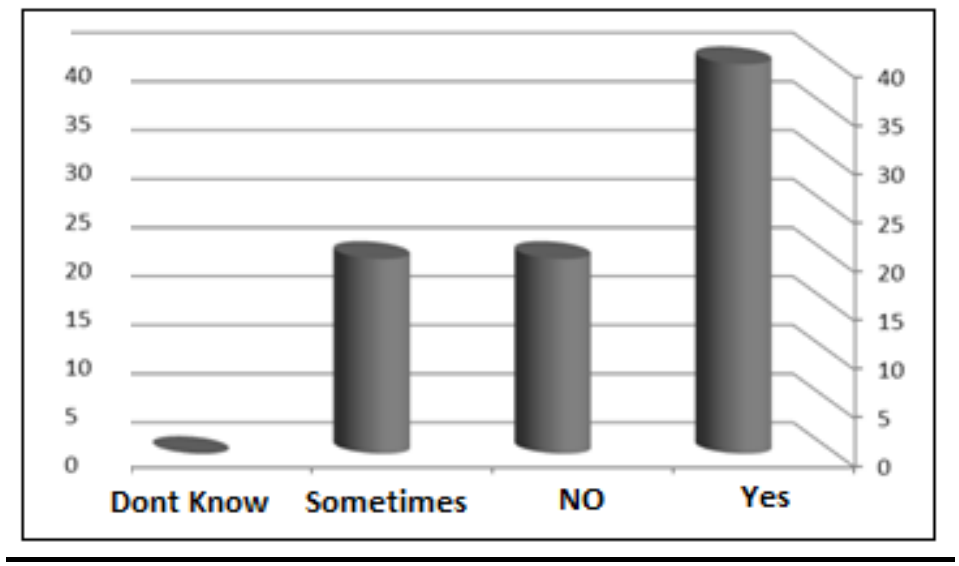

Figure 11: The design errors

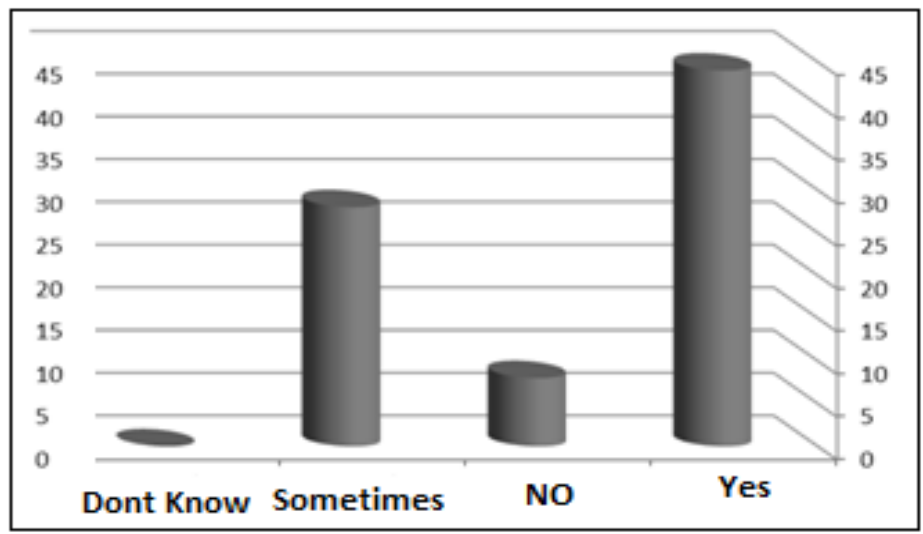

Figure 12: Misjudgment of space areas

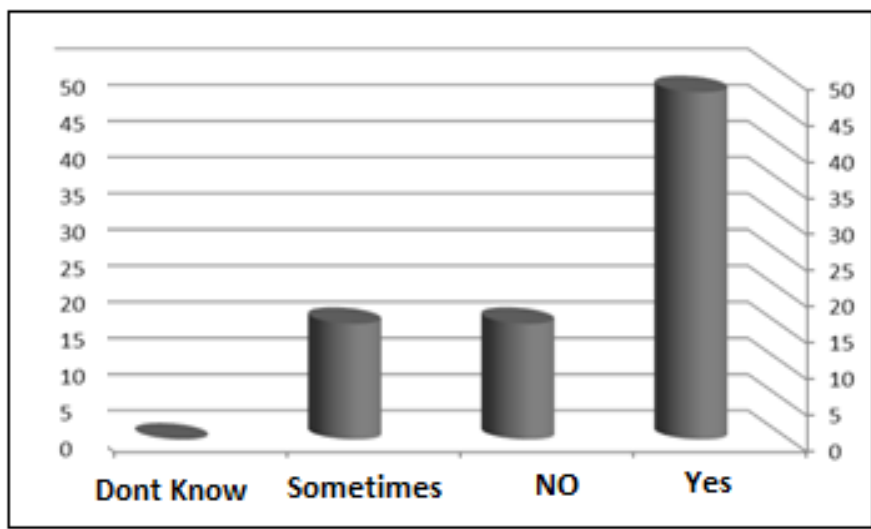

Figure 13: The construction errors

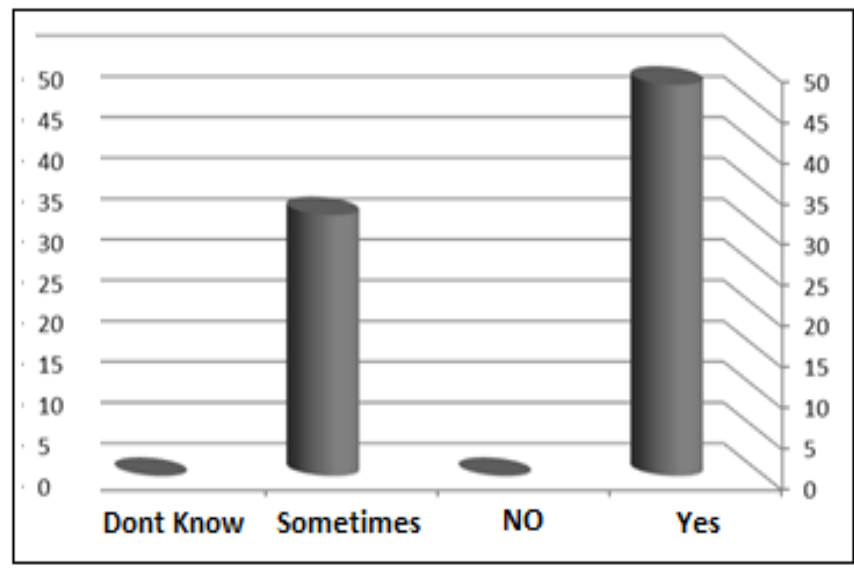


Figure 14: The consideration of the ambient environment - using a similar system without taking into account the surrounding environment

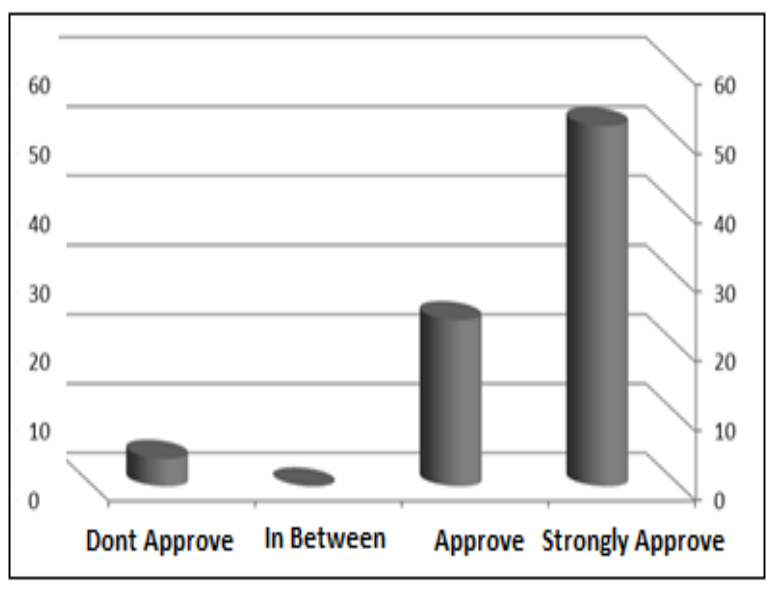

Figure 15: The function of the building should be taken into consideration in design?

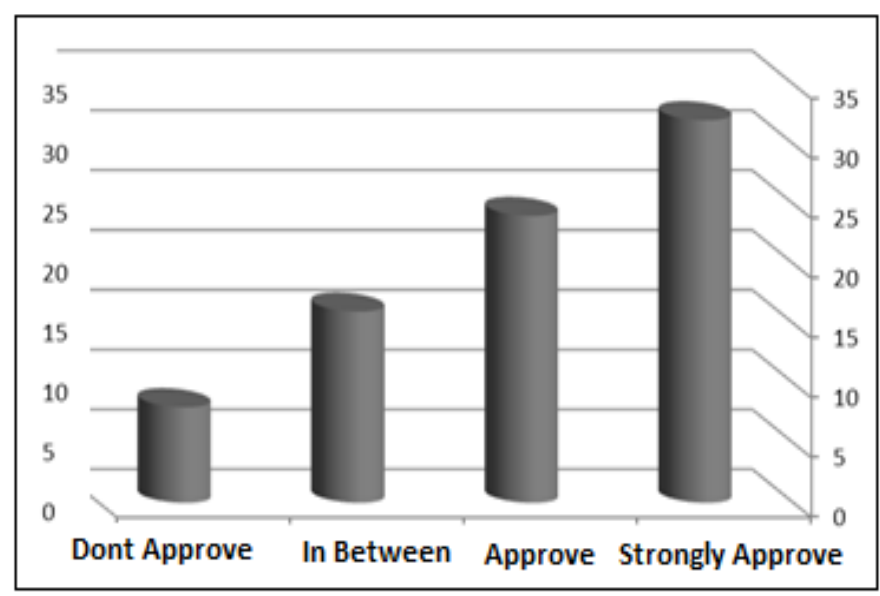

Figure 16: The type of the structural system should be taken into account in design?

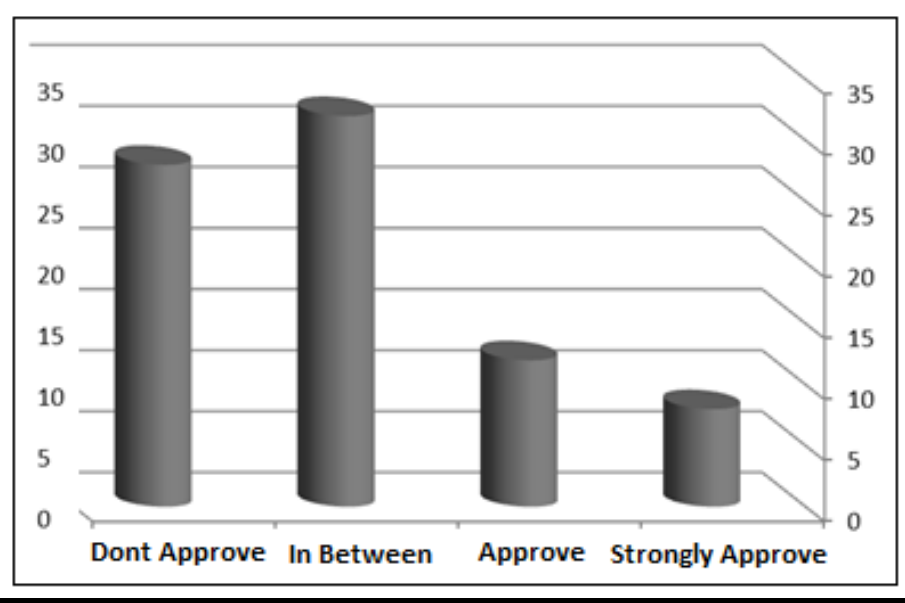

Figure 17: Structural solutions increase the effectiveness of the building and its durability to environmental conditions?

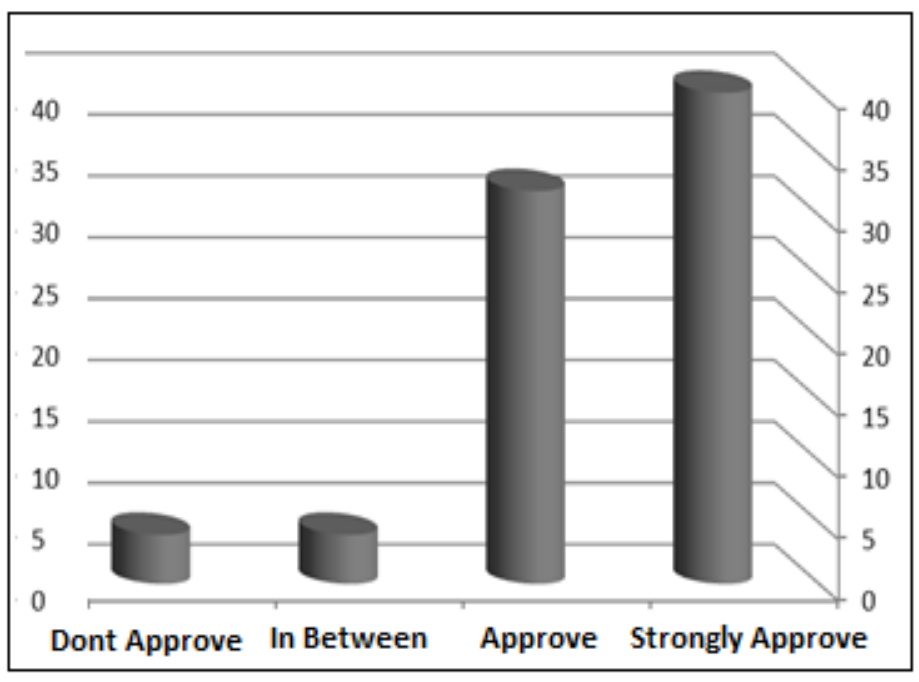

Figure 18: Joints (expansion, settlement ...etc.) should be placed in the inner space design

- The lack of proper study of the design in terms of spaces, internal areas, the function of the building, and its surrounding environment all have a significant direct impact on the handling of the internal space.

- The cost of handling the internal space increases when the surrounding environment is ignored at the time of designing.

- A large number of people were also neutral that taking constructional solutions into consideration increases the efficiency of the building and its ability to meet environmental conditions.

- A large number of study sample agreed that all aspects must be taken into consideration and that the constructional skeleton has elements that must be considered when designing.

\section{Conclusions:}

From the results of the research, questionnaire and case study, we conclude that more attention must be paid to all types of architectural and constructional solutions and factors affecting the design in order to link the architectural design with the constructional aspect and preserve all the elements, architectural details and finishing objects that give aesthetic value to the building.

This may include marble pillars, doors, cornices, chimneys, lighting elements, floors, wood cladding of walls, paints, wallpaper, furniture, whether immovable or movable, and other aspects of distinctive internal spaces and determining the proper and creative way of choosing different design and constructional solutions, taking into 
consideration the provision of appropriate environment and maintaining the economic abilities of the society and not to waste money in mistakes that can be avoided at the beginning of any design by scientific methods.

All this is done with achieving the most significant benefit of the buildings by their functional integration, and the change of the function of internal space is not favored when the architectural elements that are removed affect the durability of the building or threaten its safety. If there are mechanical or electrical systems or a visual airconditioning system, it is recommended to maintain and handle and even hide them if necessary to give the distinctive character of the internal space. When putting these additions in the inner area do not lead to the destruction or change in the nature of the constructional system, or drive to the concealment or removal of any of the distinctive elements of the space or finishing materials, taking into account the preservation of the horizontal projections and distribute the rooms as they are, especially those that give deep feeling of the spirit and character of the building by preserving the size, shape, ratios, mutual relations between rooms and corridors, and the bilateral relations between the distinctive elements of the space (furniture and lighting elements, etc.) and between the space of the room itself.

The study concluded that after conducting all the previous reviews and research, we found that the effect of a constructional skeleton on the elements of internal architectural design has a significant role since the use of construction materials increases the stability of the building against the factors that it may face. While internally and architecturally, they raise the internal and external aesthetic touch.

\section{Acknowledgement}

First of all we would like to express our great thanks to the Scientific Research Deanship at Taif University for their full support this scientific research at the university. Our thanks extended to Sudan University of Science and Technology. We are also grateful to all people and colleagues who supported us with data that we needed to complete the research.

\section{References:}

[1] Al Akam, Akram Jasem (2010). Aesthetics of Architecture and internal Design. Jordan: Dar Majdoulay.

[2] Maliki, M. (2008). Master Dissertation: internal Design of A Contemporary Saudi House from A Post-Contemporary Perspective. Kingdom of Saudi Arabia: Umm Al - Qura University.

[3] Hassan, Nubi Mohammed (2007). The Architectural Space from Modernity To Dismantle - Critical Vision. Volume 35, Issue 3. Egypt: Journal of Engineering Science Assiut University.

[4] Abboud, Ghassan Borgas (2010). The Effect of the Constructional Requirements In the Architectural Structure And its Potential for Architectural Use. Journal of the University of Damascus for Engineering Science - Volume 26: 1st ed.

[5] Atkin, B. "Intelligent Buildings; Applications of IT and Building Automation to High Technology Construction Projects" Halsted Press Book, New York. 1988

[6] Christiansson, P. "Knowledge Representations and Information flow in the Intelligent Buildings", 2000

[7] Jaffrey, R.J. "Building Performance and Occupant Productivity; Personal EnvironmentsA New Building Focus." Fourth World Congress (Tall Buildings: 2000 and Beyond), November 5-9, Hong Kong.

[8] Jedamzik, M, "Smart House, A Usable Dialog System for the control of technical System by Gesture Recognition in Home Environments". 2002.

[9] Bayan Ahmed Osman, Adil. A. M Elhassan and Awad Saad Hassan, "Intelligent Solutions in Buildings and their Impact on Elements of Architectural and Structural Design.'IOSR Journal of Mechanical and Civil Engineering (IOSR-JMCE) e-ISSN: 2278-1684,p-ISSN: 2320-334X, Volume 13, Issue 3 Ver. III (MayJun. 2016), PP 117-128 www.iosrjournals.org 